OPEN ACCESS

Edited by:

Renato Baciocchi,

University of Rome Tor Vergata, Italy

Reviewed by:

Rafael Mattos Dos Santos,

Sheridan College Institute of Technology and Advanced Learning,

Canada

Alessandra Polettini,

Sapienza University of Rome, Italy

${ }^{*}$ Correspondence:

Hannu-Petteri Mattila hmattila@abo.fi

Specialty section: This article was submitted to Carbon Capture, Storage, and Utilization, a section of the journal Frontiers in Energy Research

Received: 27 August 2015 Accepted: 28 October 2015 Published: 16 November 2015

Citation: Mattila H-P and Zevenhoven R (2015) Mineral Carbonation of

Phosphogypsum Waste for Production of Useful Carbonate and Sulfate Salts.

Front. Energy Res. 3:48. doi: 10.3389/fenrg.2015.00048

\section{Mineral Carbonation of Phosphogypsum Waste for Production of Useful Carbonate and Sulfate Salts}

\author{
Hannu-Petteri Mattila* and Ron Zevenhoven \\ Thermal and Flow Engineering Laboratory, Åbo Akademi University, Turku, Finland
}

Phosphogypsum $\left(\mathrm{CaSO}_{4} \cdot 2 \mathrm{H}_{2} \mathrm{O}, \mathrm{PG}\right)$ waste is produced in large amounts during phosphoric acid $\left(\mathrm{H}_{3} \mathrm{PO}_{4}\right)$ production. Minor quantities are utilized in construction or agriculture, while most of the material is stockpiled, creating an environmental challenge to prevent pollution of natural waters. In principle, the gypsum waste could be used to capture several hundred megatonnes of carbon dioxide $\left(\mathrm{CO}_{2}\right)$. For example, when gypsum is converted to ammonium sulfate $\left[\left(\mathrm{NH}_{4}\right)_{2} \mathrm{SO}_{4}\right]$ with ammonia $\left(\mathrm{NH}_{3}\right)$ and $\mathrm{CO}_{2}$, also solid calcium carbonate $\left(\mathrm{CaCO}_{3}\right)$ is generated. The ammonium sulfate can be utilized as a fertilizer or in other mineral carbonation processes that use magnesium silicate-based rock as feedstock, while calcium carbonate has various uses as, e.g., filler material. The reaction extent of the described process was studied by thermodynamic modeling and experimentally as a function of reactant concentrations and temperature. Other essential properties such as purity and quality of the solid products are also followed. Conversion efficiencies of $>95 \%$ calcium from PG to calcium carbonate are obtained. Scalenohedral, rhombohedral, and prismatic calcite particles can be produced, although the precipitates contain certain contaminants such as rare earth metals and sulfur from the gypsum. A reverse osmosis membrane cartridge is also tested as an alternative and energy-efficient method of concentrating the ammonium sulfate salt solution instead of the traditional evaporation of the process solution.

Keywords: ammonium sulfate, CCUS, mineral carbonation, phosphogypsum, precipitated calcium carbonate, rare earth metals, reverse osmosis

\section{INTRODUCTION}

Phosphogypsum (PG) is a waste material generated during production of phosphoric acid $\left(\mathrm{H}_{3} \mathrm{PO}_{4}\right)$ from phosphate rock rich in apatite $\left[\mathrm{Ca}_{5}\left(\mathrm{PO}_{4}\right)_{3} \mathrm{OH}\right]$ via reaction with sulfuric acid $\left(\mathrm{H}_{2} \mathrm{SO}_{4}\right)$. Chemically, PG consists primarily of calcium sulfate dihydrate, $\mathrm{CaSO}_{4} \cdot 2 \mathrm{H}_{2} \mathrm{O}$ (Table 1). Worldwide, 100-280 Mt/year PG is produced, $85 \%$ of which is stockpiled for long-term storage without further treatment (Choura et al., 2012). Depending on the origin of the apatite rock, PG may be slightly radioactive, or it may, for instance, contain some rare earth metals. Together with the huge amount produced, these contaminants often hinder efficient utilization of PG in construction and other industrial applications. Long-term stockpiling causes a risk of pollution to natural waters primarily in form of increased eutrophication and is, thus, not a preferred, 
TABLE 1 | Chemical composition (percentage of dry solids) of the gypsum samples, for PG only elements $>0.05$ wt. $\%$ listed.

\begin{tabular}{|c|c|c|c|c|c|c|c|c|c|c|c|}
\hline Sample & $\mathrm{CaSO}_{4} \cdot 2 \mathrm{H}_{2} \mathrm{O}$ & $\mathrm{MgO}$ & $\mathrm{Al}_{2} \mathrm{O}_{3}$ & SrO & $\mathrm{Nd}_{2} \mathrm{O}_{3}$ & $\mathrm{P}_{2} \mathrm{O}_{5}$ & $\mathrm{SiO}_{2}$ & $\mathrm{CeO}_{2}$ & $\mathrm{Fe}_{2} \mathrm{O}_{3}$ & Rest & $\mathbf{H}_{2} \mathbf{O}_{\text {total }}$ \\
\hline Synthetic (Merck KGaA) & $>99.0$ & $<0.02$ & - & $<0.06$ & - & - & - & - & 0.00 & $<0.92$ & 21 \\
\hline PG (Siilinjärvi) & 97.79 & 0.58 & 0.52 & 0.44 & 0.17 & 0.14 & 0.11 & 0.07 & 0.05 & 0.13 & 27 \\
\hline
\end{tabular}

$\mathrm{H}_{2} \mathrm{O}_{\text {total }}$ is the total water content as estimated from the TGA analysis, including both moisture and crystal water.

although a widely used PG treatment (Rutherford et al., 1994; Binnemans et al., 2015). The process discussed in this article would provide a feasible alternative to reduce the amount of stockpiled PG.

A well-known and extensively used production process (Vis, 1915; Witte and Wit, 1972) for ammonium sulfate $\left[\left(\mathrm{NH}_{4}\right)_{2} \mathrm{SO}_{4}\right.$, AS] utilizes calcium sulfate as a raw material (Eq. 1):

$$
\begin{aligned}
\mathrm{CaSO}_{4} & \cdot 2 \mathrm{H}_{2} \mathrm{O}(\mathrm{s})+2 \mathrm{NH}_{3}(\mathrm{aq})+\mathrm{CO}_{2}(\mathrm{aq}) \\
& \leftrightarrow\left(\mathrm{NH}_{4}\right)_{2} \mathrm{SO}_{4}(\mathrm{aq})+\mathrm{CaCO}_{3}(\mathrm{~s}) \\
& +\mathrm{H}_{2} \mathrm{O}(\mathrm{l}) ; \Delta \mathrm{H} \approx-80 \mathrm{~kJ} / \mathrm{mol} @ 20^{\circ} \mathrm{C}
\end{aligned}
$$

Solid AS is currently used as a fertilizer and as a chemical reagent. With an annual production of roughly $20 \mathrm{Mt}$, it represents a significant share of the nitrogen fertilizer market (Leip and Prud'homme, 2013). It is mainly produced using various process side streams (Jang et al., 2014). As can be seen from Eq. 1, the reaction also binds carbon dioxide as solid calcium carbonate $\left(\mathrm{CaCO}_{3}, \mathrm{CC}\right)$. Because carbon dioxide is one of the major greenhouse gases, this reaction could be utilized to mitigate the global climate change (Lee et al., 2012; Zhao et al., 2014; Pérez-Moreno et al., 2015).

Based on reaction stoichiometry, the annual production of 100-280 Mt PG could bind 26-72 $\mathrm{Mt} \mathrm{CO}_{2}$, and the already stockpiled PG noticeably larger amounts. A recently developed mineral carbonation method for magnesium silicate-based rock materials such as serpentinite would utilize the produced ammonium sulfate as a reagent, even though the AS can largely be recycled in the process (Nduagu, 2012; Zevenhoven et al., 2013).

The PG carbonation process is presented schematically in Figure 1 together with the magnesium silicate rock carbonation process, including the recycle of aqueous AS solution. As mentioned, PG carbonation as such is broadly used for AS production, though it would be essential to operate the process as environmentally friendly as possible when specifically aiming to mitigate climate change. This implies, for example, minimization of $\mathrm{CO}_{2}$ emissions from the process. In addition, obtaining both the AS and CC products in commercial qualities would create possibilities of acquiring economic benefit to facilitate a breakthrough of the PG carbonation concept as a carbon sequestration technology.

This paper studies the production of AS and CC salts using both theoretical modeling and laboratory-scale experiments. Theoretical results are verified in experiments with samples of both synthetic gypsum and Finnish industrial PG waste. The experimental work aims at producing such a high-quality CC, regarding particle morphology, crystal size, and chemical purity, that it could be utilized in commercial applications

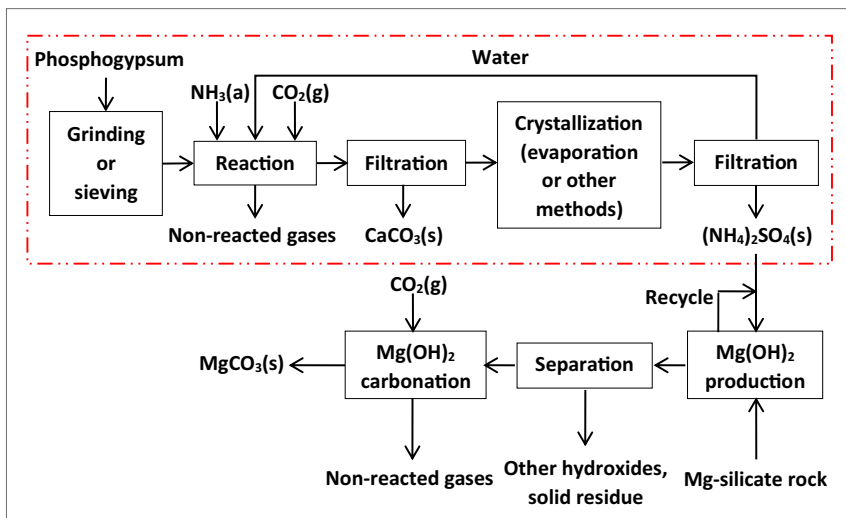

FIGURE 1 | Process concept for mineral carbonation of phosphogypsum waste (dashed rectangle) combined to a magnesium silicate rock carbonation concept. The latter part of the schematic drawn according to results by Nduagu (2012).

such as a filler material in papers and plastics as described in Mattila (2014).

Additionally, the energy-efficiency of various technologies to concentrate the AS from the aqueous solution is briefly addressed. To reduce the steam consumption during conventional evaporative crystallization and to decrease the environmental impact of the entire process, a reverse osmosis (RO) membrane cartridge is experimentally tested as a means of pre-concentrating the solution before crystallization of the AS salt.

\section{MATERIALS AND METHODS}

\section{Thermodynamic Modeling}

The governing process chemistry (Eq. 1) was modeled using Gibbs energy minimization software Outotec HSC Chemistry 8.0.3 (Roine and Kobylin, 2014). All the solid and aqueous (dissolved) inorganic compounds of $\mathrm{C}, \mathrm{Ca}, \mathrm{H}, \mathrm{N}, \mathrm{O}$, and $\mathrm{S}$ present in the HSC database were included as possible species in the model file. As a base case, $100 \mathrm{~g} / \mathrm{L}$ of $\mathrm{PG}$ [as $\left.\mathrm{CaSO}_{4} \cdot 2 \mathrm{H}_{2} \mathrm{O}(\mathrm{s})\right]$ was introduced in a total volume of $200 \mathrm{~mL}$ water at ambient pressure. The concentrations (i.e., the initial amounts) of ammonia $\left(\mathrm{NH}_{3}\right)$ and carbon dioxide $\left(\mathrm{CO}_{2}\right)$ in the aqueous phase were varied. For $\mathrm{NH}_{3}$, the modeled concentration range was $0.0<\mathrm{mol}$ $\mathrm{NH}_{3} / \mathrm{mol} \mathrm{PG}<3.5$, while for $\mathrm{CO}_{2}$ the range was $0.0<\operatorname{mol~CO} /$ mol PG $<2.0$. Based on Eq. 1, the stoichiometric amounts for these parameters are 2.0 and $1.0 \mathrm{~mol} / \mathrm{mol} \mathrm{PG}$, respectively. The calculations were performed at three different temperatures, being 20,45 , and $80^{\circ} \mathrm{C}$. The conditions were chosen because it is known that in the commercial CC precipitation processes 
different crystal morphologies precipitate at these temperatures (Mattila, 2014).

\section{Experimental Work \\ $\mathrm{CaCO}_{3}$ Precipitation Experiments}

Laboratory-scale experiments were performed to verify the obtained modeling results and to study the properties of the produced CC in more detail, focusing on the effects of the reaction temperature and $\mathrm{pH}$ as well as of the initial $\mathrm{NH}_{3}$ and $\mathrm{CO}_{2}$ concentrations. Two gypsum samples were used; besides synthetic material (Merck KGaA 1.02161.0500), PG was obtained from Siilinjärvi, Finland, where Yara Suomi Oy produces phosphoric acid for fertilizers. Thus, it was possible to compare the properties of the CC precipitated from the industrial PG, containing several impurities, to the quality of the CC made of synthetic gypsum. PG was tested both "as delivered" and after drying it overnight at $105^{\circ} \mathrm{C}$.

The chemical compositions of the materials are listed in Table 1. Besides the shown elements, the Siilinjärvi PG also contained other trace elements, including several lanthanides (La, Pr, Sm, Gd, etc.) in small $(<0.05 \%)$ amounts. The data in Table 1 are based on information from the manufacturer of the synthetic gypsum, and on XRF and ICP-MS analysis of the industrial PG. Because the PG material contained only negligible amounts (Table 1) of, e.g., phosphorus and other elements, all the calcium was assumed to be present as sulfates. The water content of the samples, including crystal water in hydrated calcium sulfates, was analyzed with TGA. Results confirmed that the material consisted primarily of calcium sulfate dihydrate. The material as received is wet, and, thus, the particle size distribution could only be determined after drying.

Different types of experiments were performed as listed in Table 2 together with the chosen reaction parameters. During the simpler procedure, defined amounts of solid and pre-dissolved aqueous reagents $\left(\mathrm{PG}, \mathrm{NH}_{3}\right.$ ) were mixed in an aqueous solution $(200 \mathrm{~mL})$ in a batch reactor with a magnetic stirrer, while $\mathrm{CO}_{2}$ gas (99.9996\%, Oy Aga Ab) was bubbled through the solution at atmospheric pressure. This approach leads to a decrease in the solution $\mathrm{pH}$ during the experiment, as $\mathrm{NH}_{3}$ is consumed from the system. The other experiment type involved conducting the carbonation at a constant $\mathrm{pH}$, mixing initially only gypsum in water $(200 \mathrm{~mL})$ while the aqueous ammonia solution $(100 \mathrm{~mL}$, $25 \%$, Merck KGaA 1.05432.1000) was gradually added during the reaction, thus, maintaining a pre-chosen, non-acidic $\mathrm{pH}$ value based on earlier work (Mattila, 2014). Ammonia addition prevented obtaining such a low solution $\mathrm{pH}$-value that the precipitated carbonates would have begun to redissolve.

In all experiments, the $\mathrm{CO}_{2}$ gas flow rate through the reaction solution was kept constant, ranging from 0.07 to $0.16 \mathrm{~L} / \mathrm{min}$. The mixing speed was chosen so that an additional speed increase did not cause any sudden changes in the solution $\mathrm{pH}$. Reaction temperature and $\mathrm{pH}$ were recorded during the experiments. After the experiments, the solutions were filtered and the collected solids were dried overnight at $105^{\circ} \mathrm{C}$. SEM (Scanning Electron Microscopy) pictures and XRF (X-Ray Fluorescence) analysis were taken of the dried samples. Because of the small sample sizes and an inaccurate XRF calibration for materials with a high calcium content, the obtained results are somewhat inaccurate, especially for the trace elements ( $<0.1 \mathrm{wt} . \%)$. Moreover, the carbonate content of the solid products was estimated according to the method of Fagerlund et al. (2010), where the pressure increase in a closed vessel during addition of concentrated $\mathrm{HCl}$ on the solids is measured.

\section{Experiments with Reverse Osmosis Membranes to Concentrate Ammonium Sulfate Salt Solutions}

While CC precipitates as solid particles, AS is obtained as dissolved ions in an aqueous solution (Eq. 1) (Witte and Wit, 1972; Jang et al., 2014). After the precipitation experiments described above, the AS concentration was approximately $0.6 \mathrm{~mol} / \mathrm{L}$ (Huhtala, 2015). Because AS has a high $\left(5.8 \mathrm{~mol} / \mathrm{L}\right.$ at $\left.25^{\circ} \mathrm{C}\right) \mathrm{solu}-$ bility in water (Lide, 2006), the amount of water to be removed to obtain AS supersaturation and to crystallize the salt is significant, roughly $90 \%$ of the total liquid volume.

Tests to concentrate AS-CC solutions were performed using a new, unused Filmtec XLE-2521 RO polyamide thin-film composite membrane cartridge. To obtain known experimental conditions, pre-mixed aqueous solutions $(10 \mathrm{~L})$ of $(1)$ pure tap water, (2) $0.1 \mathrm{~mol} / \mathrm{L} \mathrm{AS}$, and (3) $0.1 \mathrm{~mol} / \mathrm{L} \mathrm{AS}$ and $0.0002 \mathrm{~mol} / \mathrm{L}$ CC were prepared using laboratory chemicals (AS: Merck KGaA 1.01217.1000, CC: Sigma-Aldrich 398101-500G) and pumped through the membrane device using a diaphragm pump (KNFFlodos NF 1.300 KT.18S), as specified in Table 3. Concentrations in solutions (2) and (3) were of a similar order of magnitude as in the solutions obtained from the above-described precipitation experiments. During the RO experiments, the membrane device

TABLE 2 | The performed $\mathrm{CaCO}_{3}$ precipitation experiments (a)-(f).

\begin{tabular}{|c|c|c|c|c|c|c|c|c|}
\hline & Sample & Temperature $\left({ }^{\circ} \mathrm{C}\right)$ & $\mathrm{pH}^{\mathrm{a}}$ & Time (min) & Reaction type $^{b}$ & S/L-ratioc (g/L) & $\begin{array}{c}\mathrm{NH}_{3} / \mathrm{CaSO}_{4} \\
\text { (mol/mol) }\end{array}$ & $\begin{array}{c}\mathrm{CO}_{2} / \mathrm{CaSO}_{4} \\
(\mathrm{~mol} / \mathrm{mol})\end{array}$ \\
\hline (a) & $P G$ & 20 & - & 53 & $\mathrm{NH}_{3}$ & 100 & 3.8 & 1.7 \\
\hline (b) & $P G$ & 45 & 8.1 & 33 & $\mathrm{pH}$ & 160 & 3.6 & 1.7 \\
\hline (c) & PG & 20 & 7.4 & 75 & $\mathrm{pH}$ & 160 & 3.6 & 4.2 \\
\hline (d) & Synthetic & 45 & 7.2 & 139 & $\mathrm{pH}$ & 150 & 2.7 & 5.3 \\
\hline (e) & PG, dried, $<125 \mu \mathrm{m}$ & 20 & 7.4 & 80 & $\mathrm{pH}$ & 130 & 2.7 & 3.6 \\
\hline$(f)$ & PG, dried, <125 $\mu \mathrm{m}$ & 20 & 8.0 & 44 & $\mathrm{pH}$ & 85 & 4.0 & 2.9 \\
\hline
\end{tabular}

${ }^{a}$ Average $\mathrm{pH}$ during the experiment.

${ }^{b} \mathrm{NH}_{3}$ : a constant amount of reagents, $\mathrm{pH}$ : a constant $\mathrm{pH}$-value during the carbonation reaction.

cThe initial solid-to-liquid ratio; PG-to-water. 
TABLE 3 | The performed experiments with an RO membrane (1-3).

\begin{tabular}{lcc}
\hline \multicolumn{1}{c}{ Solution } & Inlet pressure (bar) & Inlet flow rate (L/h) \\
\hline (1) Tap water & 4 & 68 \\
(2) $0.1 \mathrm{M} \mathrm{AS}$ & 10 & 17 \\
(3) $0.1 \mathrm{M} \mathrm{AS}+0.0002 \mathrm{M} \mathrm{CC}$ & 10 & 21
\end{tabular}

reached a steady state after approximately $10 \mathrm{~min}$, after which the tests were continued for another $10 \mathrm{~min}$, giving, thus, a total time of 20 min per experiment.

The conductivity of the permeate flow was measured from samples taken with an interval of $5 \mathrm{~min}$, while the conductivity of the concentrate flow was continuously recorded during the tests to obtain information on the dynamic behavior of the membrane. After experiment (3), the $\mathrm{NH}_{4}^{+}(\mathrm{aq})$ and $\mathrm{Ca}^{2+}$ (aq) concentrations in the taken samples were measured with ion-selective electrodes (ISE, ELIT, Nico2000 Ltd.). The electric power consumption of the pump was measured using a commercially available household power consumption meter. Also the overall volume split of the solution was measured by weighing the obtained permeate and retentate solutions during the experiments. Between the tests, the membrane was returned to its original state by washing with water.

\section{RESULTS}

\section{Thermodynamic Modeling}

Figure 2 shows a summary of the results from the HSC modeling work as color mappings. In Figure 2A, the formation efficiency of solid $\mathrm{CC}$ at $20^{\circ} \mathrm{C}(\mathrm{mol} \mathrm{CC} / \mathrm{mol} \mathrm{PG})$ is presented, while Figure $2 \mathrm{~B}$ shows the corresponding results for dissolved $\mathrm{Ca}^{2+}$ ions. For comparison, Figures $2 \mathrm{C}, \mathrm{D}$ present the conversion efficiency of $\mathrm{PG}$ to solid CC at 45 and $80^{\circ} \mathrm{C}$, respectively. For these two temperatures, the plot for dissolved $\mathrm{Ca}^{2+}$ ions would be practically identical to Figure $\mathbf{2 B}$ and are, thus, not given. The graphs are drawn with the $(\mathrm{mol} \mathrm{NH} / 3 / \mathrm{mol} \mathrm{PG})$ ratio on the $x$-axis and the $\left(\mathrm{mol} \mathrm{CO}_{2} / \mathrm{mol}\right.$ $\mathrm{PG}$ ) ratio on the $y$-axis, the color mapping (color bar next to the graphs) representing the actual conversion of PG calcium to CC and dissolved $\mathrm{Ca}^{2+}$ ions. The fraction of unreacted PG calcium is at all temperatures equal to $(100 \%-\%$ PG calcium converted to $\mathrm{CC}-\% \mathrm{PG}$ calcium converted to dissolved $\mathrm{Ca}^{2+}$ ions) $/ 100 \%$.

According to the results, at $20^{\circ} \mathrm{C}$ a slightly over-stoichiometric ammonia-to-gypsum molar ratio of $>2.5$ and a carbon dioxideto-gypsum molar ratio of $>1.0$ guarantee a high conversion ( $>99 \%$ ) of the PG calcium to solid CC. Correspondingly, similar process conditions also lead to a negligible $(<0.002 \mathrm{~mol} / \mathrm{mol} \mathrm{PG})$ amount of dissolved $\mathrm{Ca}^{2+}$ ions in the solution. As can be expected, a certain excess of ammonia is required to maintain the alkalinity of the process solution and to prevent the dissolution of the formed CC.

An increase in reaction temperature reduces the absorption of $\mathrm{CO}_{2}$ gas, while simultaneously the evaporation of aqueous $\mathrm{NH}_{3}$ increases. Thus, somewhat more $\mathrm{NH}_{3}$ is required for a high $\mathrm{Ca}$ conversion from PG to CC at higher temperatures according to the HSC model. In practice and from the materials use efficiency point-of-view, low reaction temperature and a $\mathrm{NH}_{3}$ /
PG molar ratio of $\sim 2.5$ are preferably used together with a nearstoichiometric $\mathrm{CO}_{2}$ amount.

The thermodynamic modeling results also show that the solidto-liquid ratio of PG and water only has a minor decreasing effect on the calcium conversion efficiency when larger $(>100 \mathrm{~g} / \mathrm{L})$ PG-to-water ratios are used. Besides CC, no other solid products are present in the HSC results, indicating, thus, a theoretically excellent selectivity toward pure CC and AS.

\section{$\mathrm{CaCO}_{3}$ Precipitation Experiments}

Within the limits of experimental inaccuracies, the performed experiments (Table 2) confirm the HSC modeling results for the conversion efficiencies of $\mathrm{CaSO}_{4}$ to solid CC. Over-stoichiometric initial conditions regarding both $\mathrm{NH}_{3} / \mathrm{CaSO}_{4}$ and $\mathrm{CO}_{2} / \mathrm{CaSO}_{4}$ molar ratios resulted consistently in calcium conversions of $>94 \%$, based on obtained mass conversions and chemical composition analysis. Some of these experimental results are shown in Figure 2A as circles where the color of the circle is changing according to the conversion efficiency (Huhtala, 2015).

\section{Temperature and $\mathrm{pH}$ During the Experiments}

Figure 3 represents the $\mathrm{pH}$ and temperature recordings from experiment (a) with a decreasing $\mathrm{pH}$ as well as from experiments (c) and (d) at an approximately constant $\mathrm{pH}$-value. Due to the laboratory equipment and the used $\mathrm{pH}$ adjustment technique, the $\mathrm{pH}$ was slightly varying also during experiments (c) and (d). The highly exothermic nature of the reaction (Eq. 1) caused a temperature increase of up to $\sim 10^{\circ} \mathrm{C}$ in the reaction solutions during experiments (a) and (c), which may have slightly affected the formation or morphology of the CC precipitates. The gradual $\mathrm{NH}_{3}$ addition resulted in a slower temperature increase during experiment (c) in comparison to experiment (a). For experiment (d), the temperature increase was only $\sim 3^{\circ} \mathrm{C}$, because the reaction vessel was immersed in a water bath to maintain an elevated reaction temperature of $\sim 45^{\circ} \mathrm{C}$. No water bath was used in experiments (a) and (c).

\section{Composition of the Produced Solids}

A chemical composition analysis (XRF) was performed on the produced solids to estimate the behavior of the minor impurities which were detected in the original PG (Table 1) during the experiments. To compare with CC precipitates produced from $\mathrm{PG}$, also one precipitate manufactured from synthetic gypsum (d) was analyzed. As expected, the results showed that this material consisted of CC and unreacted gypsum with also the major impurities ( $\mathrm{Al}, \mathrm{Si}$ ) on a $40 \%$ lower level than in the PG-based products.

Table 4 shows the estimated transfer efficiencies (i.e., percentage of an element present in PG still present in the solid product) of selected elements from solid gypsum starting material to the solid products. In accordance with the HSC results, calcium remains almost fully in the solid phase, while magnesium, aluminum, and sulfur seem to dissolve during the process. For the trace elements of interest, no clear conclusions can be made based on this analysis because the very low concentrations are near the $\mathrm{XRF}$ detection limits. It seems that elements like strontium and neodymium are split between the aqueous and solid product 

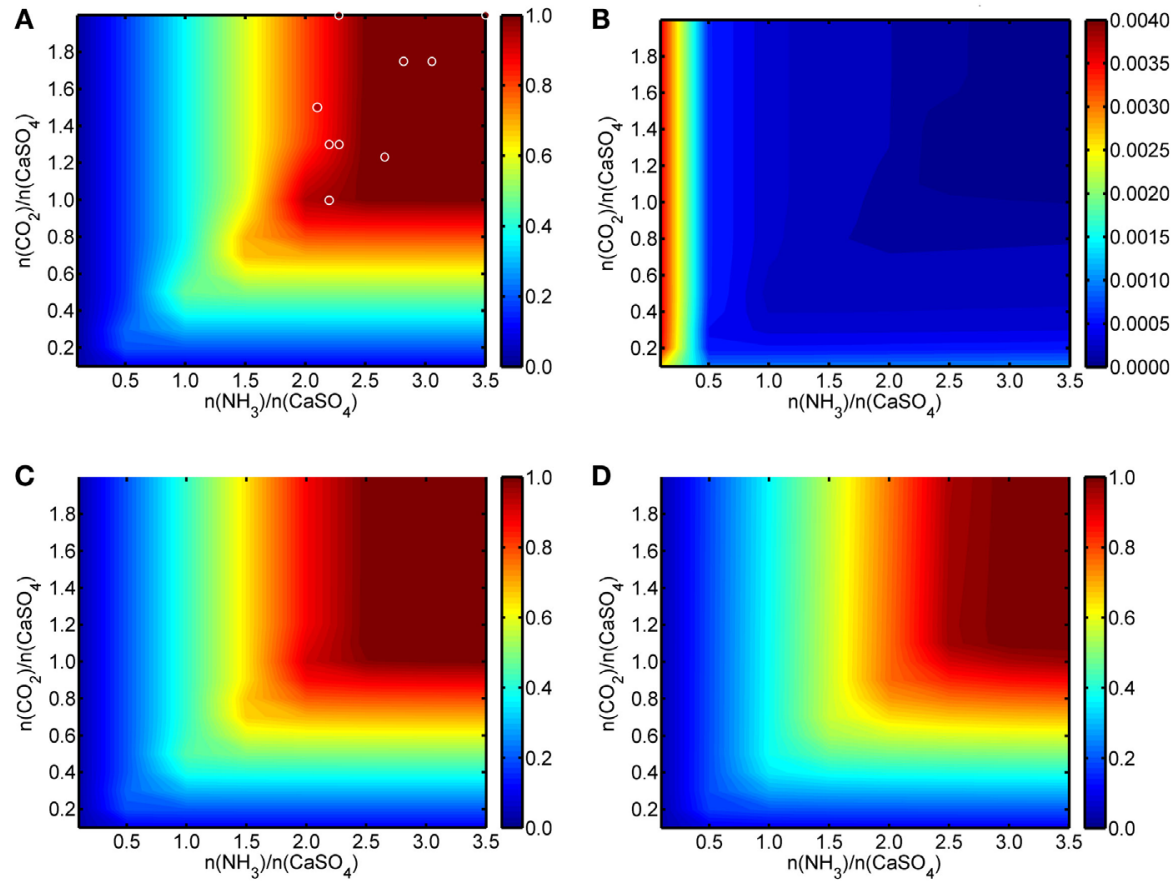

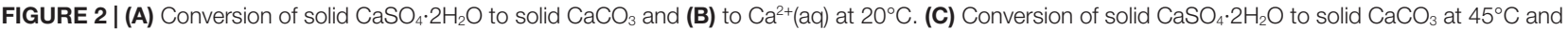
(D) at $80^{\circ} \mathrm{C}$. Figures are drawn as functions of initial $\mathrm{NH}_{3} / \mathrm{CaSO}_{4}$ and $\mathrm{CO}_{2} / \mathrm{CaSO}_{4}$ molar ratios with modeling results (color bar on the right) obtained from $\mathrm{HSC}$ Chemistry software. Dots in (A) represent examples of the experimental results obtained during the course of the work, the color indicating the obtained conversions.
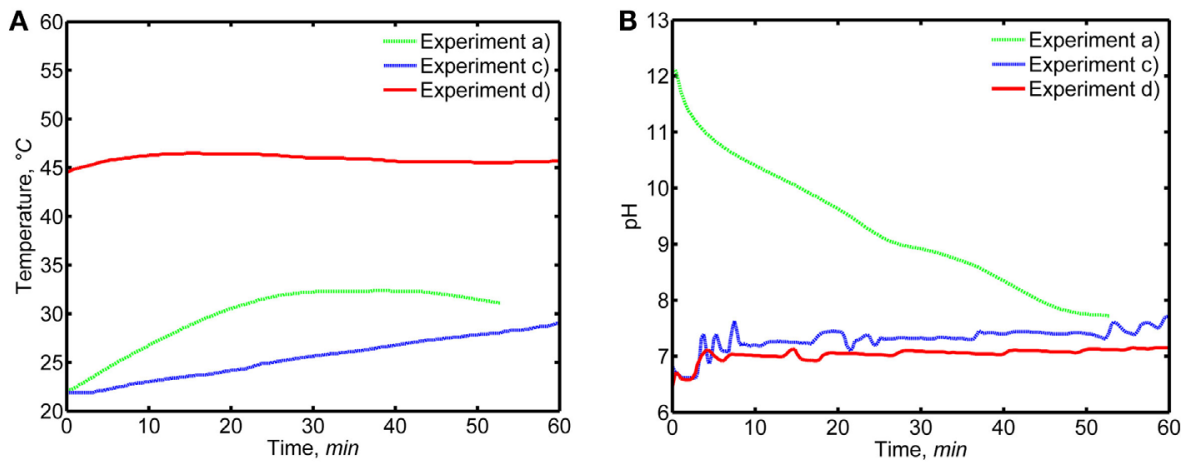

FIGURE 3 | (A) Temperature and (B) pH during the first 60 min of experiments (a), (c), and (d).

phases, and for several other elements the analysis inaccuracies result into transfer efficiencies above $100 \%$.

Table 4 also presents the $\mathrm{CaCO}_{3}$ content of the solid products as measured with the gasometric analysis method (Fagerlund et al., 2010) and the calculated conversion efficiency of PG calcium to solid CC. The carbonate contents remain above $90 \%$, except for the experiments (e) and (f), where the $\mathrm{PG}$ was dried $48 \mathrm{~h}$ at $100^{\circ} \mathrm{C}$ before the experiment. Based also on the TGA results, it seems that the drying has transformed the $\mathrm{CaSO}_{4} \cdot 2 \mathrm{H}_{2} \mathrm{O}$ into less reactive $\mathrm{CaSO}_{4} \cdot 0.5 \mathrm{H}_{2} \mathrm{O}$ (Huhtala, 2015). Because of this, the calcium conversion efficiencies are somewhat lower in experiments (e) and (f).
It was observed that although AS should, according to the HSC models, not have precipitated from the process solutions directly, small amounts ( $<3$ wt.\% as measured from the solutions after a separate washing of the dried precipitates) were present in all the samples, seemingly because the materials were mainly dried directly after the experiments without further washing.

\section{Morphology of the Produced Solids}

Figure 4 presents SEM pictures of the precipitates from experiments (a)-(f), according to Table 2. When the CC precipitation reaction is run at high $\mathrm{pH}(>8)$ and with a $\mathrm{PG}$-to-solution ratio 
TABLE 4 | CC content of the solid products (\%), Ca conversion from PG to solid CC (\%), and the transfer efficiency of various elements from PG to the solid product material (\%).

\begin{tabular}{|c|c|c|c|c|c|c|c|c|c|c|c|c|}
\hline & $\mathrm{CaCO}_{3}$ & Ca conversion & $\mathrm{Ca}$ & Mg & Al & $\mathrm{Sr}$ & $\mathrm{Nd}$ & $\mathbf{P}^{\mathbf{a}}$ & $\mathrm{Si}^{\mathrm{a}}$ & $\mathrm{Ce}^{\mathrm{a}}$ & $\mathrm{Fe}^{\mathrm{a}}$ & S \\
\hline (a) & 97 & 99 & 97 & $<1$ & 6 & 23 & 25 & 135 & 21 & 132 & 184 & 2 \\
\hline (c) & 92 & 97 & 95 & 2 & 5 & 21 & 24 & 123 & 26 & 127 & 173 & 3 \\
\hline (d) & 96 & 98 & 103 & 0 & - & 0 & - & - & - & - & - & 2 \\
\hline (e) & 84 & 94 & 98 & $<1$ & 9 & 24 & 27 & 142 & 19 & 134 & 169 & 6 \\
\hline$(f)$ & 82 & 95 & 98 & 0 & 8 & 24 & 26 & 141 & 18 & 133 & 175 & 5 \\
\hline
\end{tabular}

aPoor accuracy due to small amounts.

\section{A}

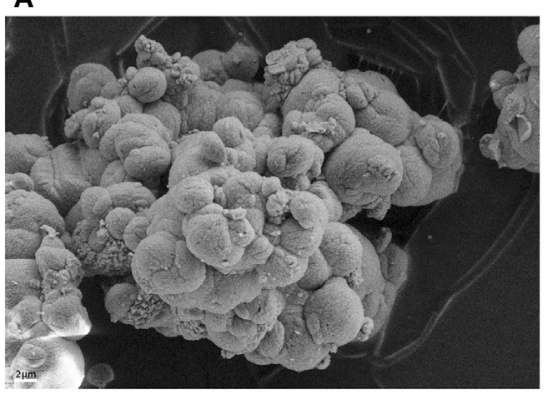

C

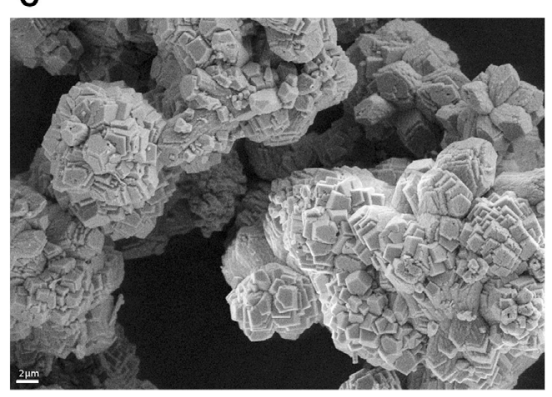

E

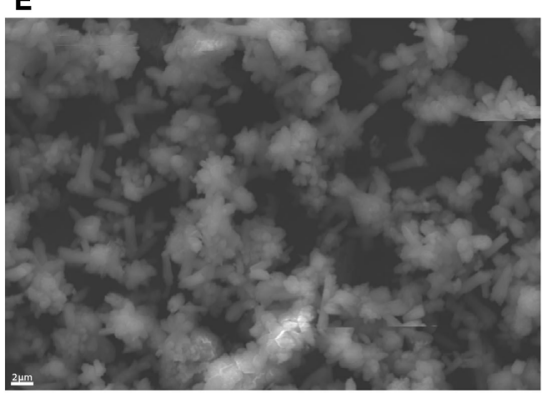

B

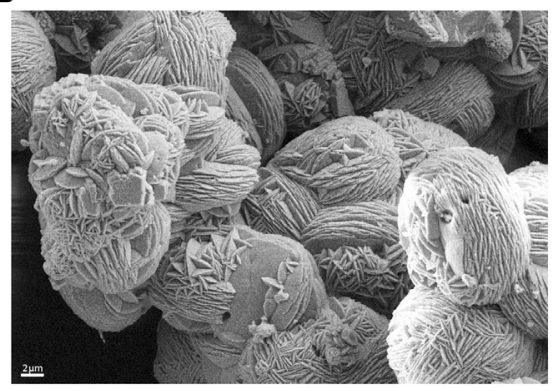

D

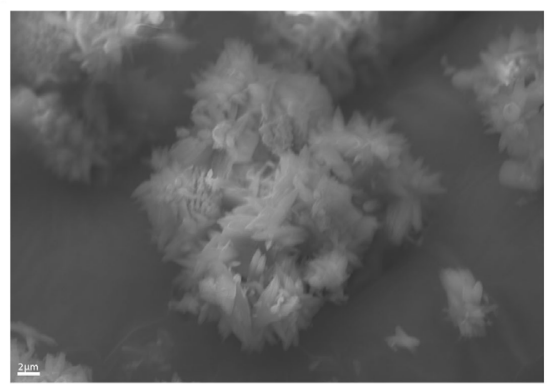

$\mathbf{F}$

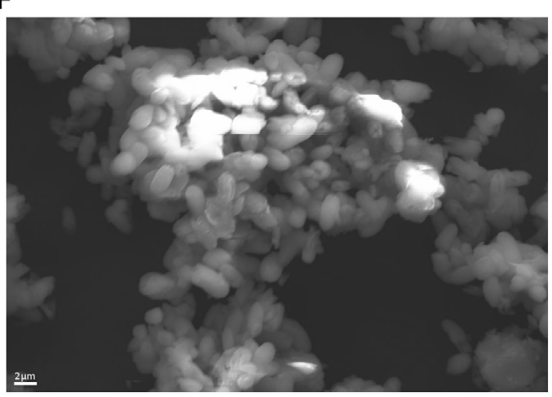

FIGURE 4 | SEM pictures of the produced carbonates. Scale bars $2 \mu \mathrm{m}$ in (A-F).

above $100 \mathrm{~g} / \mathrm{L}$, as well as with a $\mathrm{CO}_{2} / \mathrm{CaSO}_{4}$ molar ratio of $1.7 \mathrm{~mol} /$ $\mathrm{mol}$, the precipitate consists of clustered vaterite particles, the so-called framboids (a,b). At $45^{\circ} \mathrm{C}$, the vaterite particles form a disk-like surface (b).

A longer reaction time $(>1 \mathrm{~h})$ at $20^{\circ} \mathrm{C}$ and excess $\mathrm{CO}_{2}(4.2 \mathrm{~mol} /$ $\mathrm{mol} \mathrm{Ca})(\mathrm{c})$ favor the transformation of vaterite to clustered rhombohedral calcite. A long reaction time $(>2 \mathrm{~h})$ combined with an elevated temperature $\left(45^{\circ} \mathrm{C}\right)$ and a $\mathrm{NH}_{3}$ amount of $2.7 \mathrm{~mol} / \mathrm{mol}$ results into formation of scalenohedral calcite particles (d).

In experiment (e), CC particles with a crystal form resembling a mixture of rod-like calcium sulfate and scalenohedral calcite were obtained. A moderate reaction time, $\mathrm{pH}$, and $\mathrm{CO}_{2}$ amount with a somewhat lower solid-to-liquid ratio yielded a prismatic form of calcite precipitate (f). As mentioned above, the 
precipitates (e) and (f) contain more unreacted PG than the other products.

\section{Experiments with Reverse Osmosis Membranes to Concentrate Ammonium Sulfate Salt Solutions}

Table 5 summarizes the results from the RO membrane tests. Roughly 40 wt.\% of the feed salt solution volume was obtained as the permeate stream, when the device was operated at a pressure of 10 bar. According to the ISE measurements (experiment 3), the $\mathrm{NH}_{4}{ }^{+}$(aq) concentration was reduced by $97 \%$ in the permeate stream. Thus, assuming that no accumulation occurred inside the membrane cartridge, the concentrate stream had a concentration of $0.17 \mathrm{~mol} / \mathrm{L} \mathrm{NH}_{4}{ }^{+}(\mathrm{aq})$ after the experiment. Regarding $\mathrm{Ca}^{2+}(\mathrm{aq})$, the corresponding values are a reduction of $99 \%$ in the permeate stream and a concentration of $0.0004 \mathrm{~mol} / \mathrm{L}$ in the concentrate stream. The overall conductivity was reduced from $18.6 \mathrm{mS} / \mathrm{cm}$ in the inflow to $0.4 \mathrm{mS} / \mathrm{cm}$ in the permeate (tap water $\sim 0.8 \mathrm{mS}$ / $\mathrm{cm}$ ). The concentrate conductivity was $27.6 \mathrm{mS} / \mathrm{cm}$ and the average energy consumption approximately $7.5 \mathrm{kWh} / \mathrm{m}^{3}$ of permeate water.

\section{DISCUSSION}

In general, it can be concluded that the discussed process concept has potential to be utilized for $\mathrm{CO}_{2}$ capture and climate change mitigation while producing commercially useful carbonate and sulfate salts.

\section{Improvement of CC Product Quality and Developments for the CC Precipitation Step}

Solid CC (>90\% purity) and aqueous AS were consistently produced at a near $100 \%$ conversion from PG with $\mathrm{NH}_{3}$ (a) and $\mathrm{CO}_{2}(\mathrm{~g})$ as reagents in an aqueous solution. Both thermodynamic modeling and experimental work confirmed, in agreement with, e.g., Zhao et al. (2014), that slightly over-stoichiometric amounts of both ammonia and carbon dioxide are adequate for an efficient conversion of PG to solid CC at the here chosen, near ambient process temperature and pressure. It seems feasible to utilize PG without any pretreatments such as drying, because the drying decreased the PG conversion to CC, also maintaining the rod-like crystal morphology typical for gypsum particles.

Unlike previously reported in the literature, the particle morphology of the CC precipitates has now been successfully

TABLE 5 | Experimental results obtained with the RO device.

\begin{tabular}{lcclc}
\hline Solution & $\begin{array}{c}\text { Permeate } \\
\text { flow (\%) }\end{array}$ & $\begin{array}{l}\text { Permeate } \\
\mathbf{N H}_{4}^{+}(\mathbf{a q}) \\
\text { (\% of input) }\end{array}$ & $\begin{array}{c}\text { Permeate } \mathrm{Ca}^{2+}(\mathrm{aq}) \\
\text { (percentage of } \\
\text { input) }\end{array}$ \\
\hline (1) & Tap water & 53 & - & - \\
(2) & $0.1 \mathrm{M} \mathrm{AS}$ & 34 & Not measured & - \\
(3) & $\begin{array}{l}\text { 0.1M AS } \\
+0.0002 \mathrm{M} \mathrm{CC}\end{array}$ & 43 & 3 & 1
\end{tabular}

steered toward the more valuable forms by carefully choosing the precipitation conditions such as concentrations of the starting materials, reaction temperature, and reaction time. The more advanced CC morphologies (scalenohedral, rhombohedral, or prismatic calcite instead of vaterite) were obtained in the experiments where a constant, near-neutral $\mathrm{pH}$ was maintained in the reactor by feeding both $\mathrm{NH}_{3}(\mathrm{a})$ and $\mathrm{CO}_{2}(\mathrm{~g})$ continuously to the system. Especially the scaleno- and rhombohedral forms of calcite are known to be valuable in commercial applications (Mattila, 2014).

In fact, for both the control of the process $\mathrm{pH}$ and losses of ammonia, it is beneficial to feed the $\mathrm{NH}_{3}$ (a) continuously into the reactor at a moderate $\mathrm{pH}$. This reduces the amount of free ammonia in the process solution and makes it theoretically possible to avoid a sulfuric acid scrubber for the gas stream exiting the reactor. Otherwise, in large-scale process using flue gas with $<20 \% \mathrm{CO}_{2}$, such a unit would become necessary to capture the evaporated $\mathrm{NH}_{3}$.

Future research will focus more on solutions with a higher solid-to-liquid ratio and their possible effects on the CC particle morphology. Additionally, a better control on the effect of the various parameter combinations on the particle quality is required before a larger scale application focusing on production of higher quality CC can be planned.

Several impurities that are present in the PG, including lanthanide trace elements, seem to accumulate in the CC precipitate. A feasible topic for future research is to focus on separating these contaminants, especially the rare earth metals, from the carbonate material. This would, besides purifying the carbonate product, also create a valuable side product for the process. It might be possible to separate the contaminants with, e.g., density-based separation technologies. Namely, during the experiments it was observed that small, dark particles were formed and they remained mixed with the otherwise white carbonates. Due to the small amounts of solids in the experiments, no separation tests were performed as a part of this study. In addition, the Finnish PG is comparatively pure, but it would be of interest to apply the developed processing methods to more contaminated samples of PG and to study the properties of the produced salts.

\section{Energy-Efficiency of Aqueous AS Salt Solution Concentration Methods}

The performed laboratory-scale tests for desalination of the process solution using an $\mathrm{RO}$ membrane gave promising results regarding the possibility to reduce the energy demand of the solid AS production compared to evaporative crystallization processes. As mentioned, the obtained average consumption of (electrical) energy was measured to approximately $7.5 \mathrm{kWh} / \mathrm{m}^{3}$ of produced permeate water with the laboratory equipment.

Literature sources list the energy demand of, e.g., a traditional three-effect water evaporation process for ammonium sulfate separation to $300 \mathrm{kWh} / \mathrm{m}^{3}$ permeate, while a mechanical vapor recompression process is mentioned to vary in the range of $90-150 \mathrm{kWh} / \mathrm{m}^{3}$, depending on the concentration of the AS solution leaving the process and on the configuration of the process setup (Han et al., 2014). 
Because AS solutions contain larger and divalent sulfate ions, purification of AS solutions is likely to require more energy than that of sodium chloride solutions. For $\mathrm{NaCl}$ solutions, unlike the membrane-based processes, distillation or flash processes were found to also require noticeable amounts of thermal energy (100-300 MJ/m³) (Al-Karaghouli and Kazmerski, 2013).

\section{Future Work on the Membrane Separations}

The long-term operability of membrane separators for AS recovery remains as an open question, and should be addressed in the future, because an essential difference between AS solution treatment and seawater desalination is the interest in obtaining solid AS particles instead of a clean permeate stream only. Still, membranes could be used together with evaporative crystallizer units, reducing the total amount of required thermal energy.

If a membrane device efficiently prevents both the $\mathrm{NH}_{4}{ }^{+}$(aq) and $\mathrm{Ca}^{2+}(\mathrm{aq})$ ions from penetrating the membrane, as was observed during the experiments, AS and CC will concentrate in the retentate stream. Eventually, a reverse reaction of Eq. 1 will occur, AS and CC reacting back to solid gypsum, blocking

\section{REFERENCES}

Al-Karaghouli, A., and Kazmerski, L. L. (2013). Energy consumption and water production cost of conventional and renewable-energy-powered desalination processes. Renew. Sustain. Energ. Rev. 24, 343-356. doi:10.1016/j. rser.2012.12.064

Binnemans, K., Jones, P. T., Blanpain, B., Van Gerven, T., and Pontikes, Y. (2015). Towards zero-waste valorization of rare-earth-containing industrial process residues: a critical review. J. Clean. Prod. 99, 17-38. doi:10.1016/j. jclepro.2015.02.089

Choura, M., Maalouf, F., Keskes, M., and Cherif, F. (2012). "Sulphur matrix from phosphogypsum: a sustainable route to waste valorization," in Beneficiation of Phosphates: New Thought, New Technology, New Development, eds Zhang P., Miller J. D., and El-Shall H. (Englewood, CO: Society for Mining, Metallurgy and Exploration, Inc.), 297-302.

Fagerlund, J., Zevenhoven, R., Huldén, S.-G., and Södergård, B. (2010). Gasometric determination of $\mathrm{CO}_{2}$ released from carbonate materials. J. Chem. Educ. 87, 1372-1376. doi:10.1021/ed1001653

Han, D., He, W., Yue, C., Pu, W., and Liang, L. (2014). Analysis of energy saving for ammonium sulfate solution processing with self-heat recuperation principle. Appl. Therm. Eng. 73, 641-649. doi:10.1016/j. applthermaleng.2014.08.026

Huhtala, P. (2015). Carbonation of Phosphogypsum. M.Sc. Thesis, Åbo Akademi University, Turku.

Jang, Y. N., Ryu, K. W., and Lee, M. G. (2014). Production Method for High-Purity Calcite and Ammonium Sulphate by Using Gypsum. US Patent Application 2014/0161692 A1.

Lee, M. G., Jang, Y. N., Ryu, K. W., Kim, W., and Bang, J. (2012). Mineral carbonation of flue gas desulfurization gypsum for $\mathrm{CO}_{2}$ sequestration. Energy 47, 370-377. doi:10.1016/j.energy.2012.09.009

Leip, A., and Prud'homme, M. (2013). "Integrating nitrogen fluxes at the European scale," in The European Nitrogen Assessment: Sources, Effects and Policy Perspectives, eds Sutton M. A., Howard C. M., Erisman J. W., Billen G., Bleeker A., Grennfelt P., et al. (Cambridge: Cambridge University Press), 345-378.

Lide, D. R. (2006). CRC Handbook of Chemistry and Physics - 87th edition 20062007. Boca Raton, FL: Taylor \& Francis Group, LLC. the membrane element and causing maintenance requirements. Also, the required inlet pressure (Table 3 ) increases rapidly with increasing salt amounts, which might cause operational difficulties at higher AS concentrations.

\section{ACKNOWLEDGMENTS}

Contributions: besides the authors, the M.Sc. students, Pekka Huhtala, Masoud Vahedi, and Mikael Virtanen at ̊AU, are acknowledged for performing the experimental work and calculations reported in this article. ICP-MS, SEM, TGA, and XRF analyses were performed by Paul Ek, Tor Laurén and Linus Silvander, Peter Backman as well as Sören Fröjdö, all at ÅAU.

\section{FUNDING}

This work was carried out with funding from the Environmental Scholarship Fund of Ekokem Oyj (Ekokem Oyj:n Ympäristöstipendirahasto), Finland. Yara Suomi Oy, Siilinjärvi Plant, Finland is acknowledged for providing the material for experiments.

Mattila, H.-P. (2014). Utilization of Steelmaking Waste Materials for Production of Calcium Carbonate $\left(\mathrm{CaCO}_{3}\right)$. Doctoral Dissertation. Åbo Akademi University, Turku.

Nduagu, E. (2012). Production of $\mathrm{Mg}(\mathrm{OH})_{2}$ from $\mathrm{Mg}$-Silicate Rock for $\mathrm{CO}_{2}$ Mineral Sequestration. Doctoral Dissertation. Åbo Akademi University, Turku.

Pérez-Moreno, S. M., Gázquez, M. J., and Bolívar, J. P. (2015). $\mathrm{CO}_{2}$ sequestration by indirect carbonation of artificial gypsum generated in the manufacture of titanium dioxide pigments. Chem. Eng. J. 262, 737-746. doi:10.1016/j. cej.2014.10.023

Roine, A., and Kobylin, P. (2014). HSC Chemistry 8.0. Pori: Outotec Research Center.

Rutherford, P. M., Dudas, M. J., and Samek, R. A. (1994). Environmental impacts of phosphogypsum. Sci. Total Environ. 149, 1-38. doi:10.1016/0048-9697(94)90002-7

Vis, G. N. (1915). Process of Manufacturing Ammonium Sulfate. US Patent 1152244.

Witte, J. F., and Wit, J. J. (1972). Manufacture of Ammonium Sulfate from Gypsum. US Patent 3687620.

Zevenhoven, R., Fagerlund, J., Nduagu, E., Romão, I., and Highfield, J. (2013). "Stepwise serpentinite carbonation using the Åbo Akademi route - status and latest developments," in Proceedings of the 4th International Conference on Accelerated Carbonation for Environmental and Materials Engineering (ACEME), eds Nasser R., Santos R., Cizer Ö, and van Gerven T. (Leuven: KU Leuven), 391-400.

Zhao, H., Li, H., Bao, W., Wang, C., and Li, S. (2014). Experimental study of enhanced phosphogypsum carbonation with ammonia under increased $\mathrm{CO}_{2}$ pressure. J. $\mathrm{CO}_{2}$ Util. 11, 10-19. doi:10.1016/j.jcou.2014.11.004

Conflict of Interest Statement: The authors declare that the research was conducted in the absence of any commercial or financial relationships that could be construed as a potential conflict of interest.

Copyright (C) 2015 Mattila and Zevenhoven. This is an open-access article distributed under the terms of the Creative Commons Attribution License (CC BY). The use, distribution or reproduction in other forums is permitted, provided the original author(s) or licensor are credited and that the original publication in this journal is cited, in accordance with accepted academic practice. No use, distribution or reproduction is permitted which does not comply with these terms. 